Santiago Poy*

\title{
CAMBIOS EN EL MERCADO DE TRABAJO, EN LAS POLÍTICAS SOCIALES Y SUS EFECTOS EN LAS CONDICIONES DE VIDA FAMILIARES EN LA ARGENTINA POST-REFORMAS (2003-2014)*****
}

\begin{abstract}
"El estudio de la reproducción de los individuos y de sus capacidades debe enmarcarse en el contexto de la heterogeneidad de nuestras sociedades. La penetración y el desarrollo desigual del capitalismo en la región [latinoamericana] determina los requerimientos de la acumulación de capital que, a su vez, contribuyen a la constitución y conservación de diversas formas de utilización de la fuerza de trabajo"
\end{abstract}

Oliveira y Salles (2000: 629).

* Becario doctoral del Consejo Nacional de Investigaciones Científicas y Técnicas en el Programa del Observatorio de la Deuda Social Argentina (CONICETUCA). E-mail: santiagopoy@hotmail.com.

** Este artículo fue elaborado en el marco del proyecto europeo INCASI, International Network for Comparative Analysis of Social Inequalities, financiado por el programa para la investigación y la innovación Horizon 2020 bajo Marie Skłodowska-Curie Actions (MSCA) N 691004 y coordinado por el Dr. Pedro López Roldán. Este artículo refleja la opinión del autor. Las instituciones referidas no son responsables del uso que pueda hacerse de la información que contiene.

*** Este trabajo constituye un avance de investigación de mi tesis doctoral. Una versión previa se presentó en el XIII Congreso Nacional de Estudios del Trabajo, realizado en Buenos Aires en agosto de 2017. Se inscribe en el marco del proyecto UBACYT "Heterogeneidad estructural, desigualdad distributiva y nuevas marginalidades sociales. Reproducción histórica de un modelo socioeconómico cada vez más concentrado y excedentario en fuerza de trabajo (19742014)", que se desarrolla en el Programa Cambio Estructural y Desigualdad Social con sede en el Instituto de Investigaciones Gino Germani de la UBA, y del Programa del Observatorio de la Deuda Social Argentina, UCA. 


\section{INTRODUCCIÓN}

El ciclo post-reformas estructurales iniciado tras la crisis del modelo de convertibilidad en la Argentina estuvo atravesado por transformaciones en el mercado de trabajo y en las políticas sociales de transferencias de ingresos. Por un lado, la literatura ha constatado una recomposición de los niveles de empleo y una reducción de la precariedad laboral con respecto a los años noventa, si bien se reconoce a la heterogeneidad estructural y a la segmentación del mercado de trabajo como rasgos duraderos de la dinámica ocupacional urbana (Beccaria y Maurizio, 2012; Groisman, 2013; Salvia, Vera y Poy, 2015; Salvia, 2016; Poy, 2017). Por otra parte, en el pasado reciente se verificó una modificación institucional y una expansión del sistema de políticas sociales, asociadas a la mayor cobertura previsional, la reestatización del sistema y la ampliación de los programas de transferencias monetarias condicionadas (Andrenacci, 2016; Curcio y Beccaria, 2013; Danani y Beccaria, 2013; Filgueira, 2015).

Un aspecto poco atendido por la literatura en los años recientes remite al modo en que estos dos procesos operaron simultáneamente sobre los cambios en las condiciones de vida familiares. En general, es poco habitual que los estudios sobre el mercado de trabajo consideren a los hogares como unidad de análisis o bien, si lo hacen -como los estudios sobre los cambios en la morfología de las clases sociales-, no suelen explicitar el papel de las políticas sociales como elemento clave en la reconfiguración reciente de la distribución del ingreso (Beccaria y Groisman, 2009; Benza, 2016; Chávez Molina y Sacco, 2015; Donza, 2015; Dalle et al., 2015; Groisman, 2011). Por su parte, las investigaciones que abordan los efectos distributivos de las políticas sociales en la Argentina han priorizado una mirada agregada, sin describir su asociación con distintos modos de participación laboral de distintos grupos de individuos y hogares (Rofman y Oliveri, 2012; Salvia, Poy y Vera, 2016; Trujillo y Villafañe, 2012). Este "desacople" (Heintz y Razavi, 2012) entre el análisis del mercado laboral y los estudios de política social no es privativo de nuestro contexto, se asocia a los cambios verificados en las pautas de inserción laboral en las últimas décadas y requiere de la reconstrucción de sus relaciones recíprocas.

Este capítulo propone articular los estudios sobre la estructura social del trabajo con el análisis de las políticas sociales. El eje que hace posible esta articulación es el interés por los cambios en las condiciones de reproducción y el acceso al bienestar de los hogares. Para ello, se considera simultáneamente la participación de las unidades domésticas en la estructura social del trabajo -espacio comúnmente asociado a la distribución primaria del ingreso- y el acceso a diferentes recursos provenientes de la intervención social del Estado -lo que ha- 
bitualmente se asocia con la distribución secundaria-. Precisamente, interesa evaluar la existencia de cambios en las formas de reproducción de las unidades domésticas como consecuencia de alteraciones en la importancia relativa de la participación en la distribución primaria y secundaria del ingreso. Retomando un enfoque teórico centrado en la heterogeneidad estructural del sistema económico-ocupacional (Salvia, 2012, 2016) ${ }^{1}$ y estudios empíricos sobre su persistencia en el período post-convertibilidad (Salvia, Vera y Poy, 2015; Poy, 2017), el análisis combinado de inserción económica y política social permite caracterizar las múltiples formas por medio de las cuales los hogares participan en la distribución del producto social y evaluar el papel desempeñado por tales instrumentos en las condiciones socioeconómicas dominantes.

El capítulo avanza en torno a tres objetivos centrales. En primer lugar, se propone describir los cambios en la participación de los hogares en la estructura económico-ocupacional durante el período post-reformas como aproximación a un determinante clave de las condiciones de vida. En segundo lugar, el capítulo busca describir el alcance diferencial que tuvieron los cambios en la intervención social del Estado sobre los hogares según su posición en la estructura ocupacional, y evaluar la cobertura de distintos instrumentos de política social entre diferentes grupos socio-ocupacionales. En tercer lugar, se propone examinar los efectos conjuntos que tuvieron los cambios en el mercado laboral y en el sistema de política social sobre las condiciones de vida familiares.

La información se construyó a partir de la Encuesta Permanente de Hogares (EPH) del Instituto Nacional de Estadística y Censos (INDEC) para el período 2003-2014, tomando los cuartos trimestres de cada año. La EPH tiene algunas limitaciones para identificar políticas sociales y, por ello, se llevaron adelante distintas metodologías de estimación que se describen en el Anexo Metodológico. El interés de este trabajo se centra en el período post-reformas o post-convertibilidad, el cual se inicia con la crisis económico-financiera de 2001-2002. Establecemos dos períodos analíticos relevantes para el análisis: (i) en sus primeros años, este ciclo se caracterizó por altos niveles de crecimiento económico sostenidos tanto en el uso de la capacidad instalada como en la expansión de las exportaciones en un contexto de altos precios

1 El concepto de heterogeneidad estructural es una noción clave del pensamiento estructuralista latinoamericano que busca aproximarse a las características de la estructura productiva de los países de la región con particular interés en la dinámica de absorción de fuerza de trabajo por parte de los sectores más dinámicos de la economía (Salvia, 2012). 
de las commodities. Al nivel del mercado de trabajo, ello se tradujo en una elevada elasticidad empleo-producto, propiciada por la demanda generada por actividades productivas orientadas al mercado interno. Este ciclo empezó a mostrar signos de debilidad en los años 2007-2008, cuando el mercado de trabajo perdió dinamismo y comenzó a aumentar la inflación (Beccaria y Maurizio, 2012; Gaggero, Schorr y Wainer, 2014). (ii) Desde entonces, el crecimiento fue más errático, lento o directamente nulo, registrándose períodos de recesión económica. En general, se destaca lo ocurrido en los años posteriores a 2011 cuando se hicieron presentes las mayores dificultades debidas a la reaparición de la "restricción externa" provocada por la insuficiente cantidad de divisas para afrontar la sustitución de importaciones (Gaggero, Schorr y Wainer, 2014).

La primera sección del trabajo localiza los principales conceptos en discusión y ubica la construcción operativa de inserciones económico-ocupacionales de los hogares y los tipos de política social que pudieron ser identificados. La segunda sección analiza los cambios en las formas de participación económico-ocupacional de los hogares, dando cuenta de los principales cambios y continuidades registrados en el período. La tercera sección repasa muy brevemente las transformaciones en el sistema de políticas sociales en el período post-reformas y señala cómo se tradujeron a nivel de los hogares. En la cuarta sección se presenta un modelo de descomposición de la variación del ingreso per cápita familiar que permite sopesar el papel que fuentes laborales y políticas sociales jugaron en el bienestar de las unidades domésticas. El capítulo se cierra con un conjunto de reflexiones finales a la luz de las preocupaciones que motivaron este trabajo.

\section{REPRODUCCIÓN DE LOS HOGARES, HETEROGENEIDAD ESTRUCTURAL Y POLÍTICA SOCIAL: NOTAS TEÓRICO-METO- DOLÓGICAS}

Los hogares ${ }^{2}$ constituyen el ámbito en el cual se organiza la reproducción y el mantenimiento cotidiano y generacional de la población (Oliveira y Salles, 2000). Con el propósito de optimizar sus condiciones de reproducción, en los hogares se define la participación en el mercado de trabajo, la utilización de recursos económicos y la organización de las prácticas de consumo (Torrado, 2006 [1982]). Diferentes perspec-

2 En este trabajo, definimos a los hogares como "una persona o grupo de personas, parientes o no, que habitan bajo un mismo techo en un régimen de tipo familiar; es decir, comparten sus gastos en alimentación u otros esenciales para vivir" (INDEC, 2003: 6). A su vez, utilizamos de modo equivalente los términos "familia", "hogar" y "unidad doméstica". Si bien no desconocemos sus diferencias, lo hacemos a los fines de facilitar la lectura. 
tivas conceptuales señalan la interacción que se produce entre las unidades domésticas -atravesadas por clivajes de género y generación-, el mercado y el Estado en relación con la reproducción y el bienestar. No obstante, se reconoce el carácter dominante que el mercado de trabajo tiene en la determinación de las condiciones de vida familiares, sobre todo en una región como América Latina (Barba, 2007; Cortés, 2000; Danani, 2009; Esping-Andersen, 1999; Martínez Franzoni, 2005; Salvia, 2012).

Para analizar la participación de los hogares en el mercado de trabajo, adoptamos una perspectiva teórica que toma como eje las características de la estructura productiva y las relaciona con la estructura social del trabajo (Fine, 2003). Un rasgo central se asocia con la heterogeneidad estructural, aspecto clave de las economías periféricas, que se expresa en la existencia simultánea de dos "brechas" con amplias consecuencias sobre la dinámica económico-ocupacional. Por una parte, una brecha interna, que remite a la coexistencia de estratos de productividad muy diferenciada, lo que se asocia con un patrón de especialización productiva y sus dificultades para absorber y promover el cambio técnico (Infante, 2011; Salvia, 2012). Por otra parte, una brecha externa, que remite a la distancia entre las economías periféricas y la frontera tecnológica internacional (Bárcena y Prado, 2016; Infante, 2011).

El vínculo entre heterogeneidad estructural y estructura ocupacional es significativo, en tanto que, como enfatizan Bárcena y Prado (2016: 36), "las brechas de productividad se traducen en mercados de trabajo segmentados, tanto en lo que respecta al acceso a empleos como a los ingresos salariales y laborales". De acuerdo con la teoría, la heterogeneidad estructural se asocia con la insuficiente absorción de empleo en los sectores económicos más dinámicos y, por lo tanto, con la existencia de fuerza de trabajo redundante en actividades de baja productividad (Salvia, 2012). Precisamente, el sector microempresario o informal constituye el "último eslabón" de la heterogeneidad estructural, en tanto incluye un conjunto de unidades económicas que operan en mercados de "fácil entrada", con baja dotación de capital, baja productividad y dimensiones reducidas (PREALC, 1978; Tokman, 2000; Salvia, 2012). El sector microinformal opera en los "intersticios" del sector capitalista más estructurado y su dinámica se encuentra supeditada a las expansiones y contracciones de éste a la vez que establece relaciones de distinto tipo con él (Cacciamali, 2000).

Para definir las características de las inserciones económico-ocupacionales, es frecuente analizar, a la vez, su calidad, lo que alude a la existencia de distintos segmentos de empleo (Salvia, Vera y Poy, 2015). Si bien existen diversas conceptualizaciones, en este capítulo 
nos aproximamos a esta dimensión a partir de la distinción de posiciones ocupacionales precarias, definidas a partir del "alejamiento de los principales rasgos del empleo típico (también regular, normal o protegido), para lo cual se consideran dos elementos básicos de la relación laboral: estabilidad en el empleo y cobertura social" (Beccaria, Carpio y Orsatti, 2000:142). Existe una estrecha relación entre heterogeneidad estructural y calidad del empleo, en tanto son las condiciones de acumulación de las unidades productivas las que determinan -si bien no de modo único- las modalidades de contratación de la fuerza de trabajo (Bárcena y Prado, 2016; Coatz, García Díaz y Woyecheszen, 2010) $)^{3}$.

Con el propósito de dar cuenta de la participación de los integrantes de los hogares en distintas posiciones económico-ocupacionales desde esta clave analítica, se construyó una tipología de inserciones (Esquema 1) que retoma trabajos previos basados en una línea estructuralista de análisis del mercado laboral (PREALC, 1978; Salvia, 2012).

3 En este sentido, en unidades productivas del sector microinformal tienden a predominar las relaciones laborales precarias, al igual que en las empresas menos productivas del sector formal (Poy, 2017). 
Esquema 1. Inserciones económico-ocupacionales de la fuerza de trabajo.

\begin{tabular}{|c|c|c|}
\hline \multicolumn{2}{|c|}{ Inserciones económico-ocupacionales } & Definición operativa \\
\hline \multicolumn{3}{|l|}{ SECTOR FORMAL PRIVADO } \\
\hline $\begin{array}{l}\text { Empleadores, directivos } \\
\text { y profesionales }\end{array}$ & $\begin{array}{l}\text { No asalariados } \\
\text { y directivos del } \\
\text { sector formal } \\
\text { privado }\end{array}$ & $\begin{array}{l}\text { Empleadores en establecimientos formales (más } \\
\text { de } 5 \text { ocupados) o en micro-establecimientos (hasta } \\
5 \text { ocupados) pero con calificación profesional; } \\
\text { trabajadores por cuenta propia con calificación } \\
\text { profesional; y asalariados en establecimientos } \\
\text { privados en función de dirección. }\end{array}$ \\
\hline Asal. Reg. Sector Formal & Asalariados del & $\begin{array}{l}\text { Asalariados en establecimientos de más de } 5 \\
\text { trabajadores con descuento jubilatorio. }\end{array}$ \\
\hline $\begin{array}{l}\text { Asal. No Reg. Sector } \\
\text { Formal }\end{array}$ & Sector Formal & $\begin{array}{l}\text { Asalariados en establecimientos de más de } 5 \\
\text { trabajadores sin descuento jubilatorio. }\end{array}$ \\
\hline \multicolumn{3}{|l|}{ SECTOR PÚBLICO } \\
\hline $\begin{array}{l}\text { Empleados del sector } \\
\text { público }\end{array}$ & $\begin{array}{l}\text { Empleados del } \\
\text { sector público }\end{array}$ & Asalariados del sector público. \\
\hline \multicolumn{3}{|l|}{ SECTOR MICROINFORMAL (a) } \\
\hline $\begin{array}{l}\text { Patrones microempresas } \\
\text { y TCP calificados con } \\
\text { capital }\end{array}$ & $\begin{array}{l}\text { No asalariados } \\
\text { del sector }\end{array}$ & $\begin{array}{l}\text { Empleadores en micro-establecimientos (hasta } 5 \\
\text { ocupados) sin calificación profesional; trabajadores } \\
\text { por cuenta propia calificados y con capital propio. }\end{array}$ \\
\hline $\begin{array}{l}\text { TCP no calificados y/o } \\
\text { sin capital propio }\end{array}$ & informal & $\begin{array}{l}\text { Trabajadores por cuenta propia sin calificación o sin } \\
\text { capital propio. }\end{array}$ \\
\hline $\begin{array}{l}\text { Asal. Reg. Sector } \\
\text { Informal }\end{array}$ & $\begin{array}{l}\text { Asalariados } \\
\text { del sector }\end{array}$ & $\begin{array}{l}\text { Asalariados en micro-establecimientos (hasta } 5 \\
\text { ocupados) o del servicio doméstico con descuento } \\
\text { jubilatorio. }\end{array}$ \\
\hline $\begin{array}{l}\text { Asal. No Reg. Sector } \\
\text { Informal }\end{array}$ & $\begin{array}{l}\text { microempresario / } \\
\text { informal }\end{array}$ & $\begin{array}{l}\text { Asalariados en micro-establecimientos (hasta } 5 \\
\text { ocupados) o del servicio doméstico sin descuento } \\
\text { jubilatorio. }\end{array}$ \\
\hline \multicolumn{3}{|c|}{ DESOCUPADOS Y PLANES DE EMPLEO } \\
\hline $\begin{array}{l}\text { Beneficiarios de planes } \\
\text { de empleo }{ }^{(b)}\end{array}$ & \multirow{2}{*}{$\begin{array}{l}\text { Desocupados y } \\
\text { beneficiarios de } \\
\text { planes de empleo }\end{array}$} & $\begin{array}{l}\text { Ocupados cuya ocupación principal es un plan de } \\
\text { empleo }\end{array}$ \\
\hline Desocupados & & $\begin{array}{l}\text { Personas que declaran buscar activamente un } \\
\text { empleo. }\end{array}$ \\
\hline
\end{tabular}

Nota: (a) siguiendo el criterio de Monza y López (1995), se excluyó por definición algunas ramas de actividad. Aquí fueron las actividades financieras y empresariales, y la rama enseñanza y servicios de salud. / (b) Incluye a quienes declaran en la EPH que su ocupación principal es un plan de empleo (Plan Jefas y Jefes de Hogar, Argentina Trabaja, Ellas Hacen, siempre que hayan sido declarados como plan de empleo por el respondente).

Fuente: elaboración propia a partir de la EPH-INDEC. 
Además de participar en la estructura social del trabajo por medio de sus miembros ocupados, los hogares acceden a recursos que provienen de la intervención estatal. En este sentido, siguiendo a Danani (2009: 29), cabe entender a las intervenciones estatales que inciden sobre las condiciones de vida y la reproducción de la población como intervenciones sociales del Estado. Pero mientras que la política laboral "regula directamente las condiciones de venta y uso de la fuerza de trabajo" (Danani, 2009: 31. Énfasis original) y, por tanto, participa en la distribución primaria del ingreso (por ejemplo, las políticas de ingresos o de salario mínimo), la política social remite a "aquellas intervenciones sociales del Estado que producen y moldean indirectamente las condiciones de vida y de reproducción de la vida de distintos sectores y grupos sociales" (Danani, 2009: 32. Énfasis original). De esta forma, las políticas sociales son aquellas intervenciones del Estado que operan sobre la distribución secundaria del ingreso. Específicamente, en este trabajo se analizan aquellas que implican transferencias de ingresos ${ }^{4}$.

¿Qué relación conceptual existe entre mercado de trabajo y política social? Una amplia corriente teórica se centra en el rol de las políticas sociales en clave a los procesos de integración social (Donzelot, 2007). De acuerdo con estos enfoques, la política social operaría como una respuesta ante la acción disgregadora de los mercados ${ }^{5}$. Otros autores ponen énfasis en el papel de la política social como instrumento clave de los regímenes de acumulación (Fleury, 1997; O’Connor, 1977; Offe, 1984). Aquí recuperamos esta línea, de acuerdo con la cual la política social constituye un instrumento clave en términos de reproducción de la fuerza de trabajo, regulación del conflicto social y legitimación en el proceso de acumulación (Cortés y Marshall, 1991). En las sociedades latinoamericanas, con posterioridad al ajuste estructural (iniciado en los noventa), la política social habría pasado a constituir un mecanismo de creciente importancia en términos de regulación social ante la emergencia de nuevos modos de marginalidad socioeconómica originados en la heterogeneidad del sistema ocupacional (Salvia, 2007, 2016). En este sentido, cabe argumentar que los ingresos de

4 Profundizando una distinción de Esping-Andersen, Danani (2009) plantea que las políticas sociales pueden desmercantilizar necesidades o a las personas. En cuanto a lo primero, cabe incluir a las políticas que brindan servicios que, si no mediara la intervención estatal, los hogares deberían auto-proveerse (a través de trabajo no remunerado) o comprar en el mercado (por ejemplo, políticas de salud, educación, cuidados, vivienda, etc.). En cuanto a lo segundo, se incluyen las políticas que transfieren ingresos. Éstas constituyen el foco de interés aquí.

5 El supuesto subyacente en esta tradición está dado por el planteo original de Polanyi, que describió a la política social como una reacción protectora de la sociedad ante el "molino satánico" del mercado. 
política social desempeñarían un papel de "compensación" -aunque limitado- de las debilitadas capacidades de reproducción de la fuerza de trabajo que participa de las actividades económicas de baja productividad 6 .

En este capítulo, se evalúa la relación entre heterogeneidad estructural, inserción económico-ocupacional de los hogares y el papel de la política social en las capacidades de reproducción y condiciones de vida de las unidades domésticas. Con este fin, se construyó información a partir de microdatos de la Encuesta Permanente de Hogares de los cuartos trimestres de 2003 a 2014. Se asignó a los hogares la posición económico-ocupacional del principal sostén del hogar (PSH) ${ }^{7}$. Como se señaló, existen restricciones de la fuente de datos para la identificación de las políticas sociales. Ello implicó adoptar una serie de decisiones metodológicas que se especifican con detalle en el Anexo Metodológico de este trabajo. En el Esquema 2 se señalan las políticas sociales que son objeto de análisis y sus modos de captación.

\section{Esquema 2. Tipos de política social y posibilidades de captación.}

\begin{tabular}{|l|l|l|}
\hline Tipo de política social & Nombre de la política & $\begin{array}{l}\text { Tipo de } \\
\text { identificación }\end{array}$ \\
\hline $\begin{array}{l}\text { Programas de empleo } \\
\text { / Programas de } \\
\text { capacitación }\end{array}$ & $\begin{array}{l}\text { Plan Jefas y Jefes de Hogar, otros programas } \\
\text { (Argentina Trabaja, Ellas Hacen, etc.) }\end{array}$ & Directa (pp07e) \\
\hline Seguro de desempleo & Seguro de desempleo & Directa (v4_m) \\
\hline Sistema previsional & $\begin{array}{l}\text { Jubilaciones / pensiones (contributivas y no } \\
\text { contributivas) }\end{array}$ & Directa (v2_m) \\
\hline Asignaciones familiares & Sistema de asignaciones familiares & $\begin{array}{l}\text { Indirecta } \\
\text { (estimación) }\end{array}$ \\
\hline $\begin{array}{l}\text { Otras transferencias } \\
\text { monetarias } \\
\text { condicionadas }\end{array}$ & $\begin{array}{l}\text { Programa Familias para la Inclusión Social, } \\
\text { Asignación Universal por Hijo, Asignación Universal } \\
\text { por Embarazo, PROGRESAR, otras transferencias de } \\
\text { nivel subnacional no identificables }\end{array}$ & $\begin{array}{l}\text { Indirecta (a partir } \\
\text { de v5_m) }\end{array}$ \\
\hline
\end{tabular}

Fuente: Elaboración propia a partir de la EPH-INDEC.

6 Esto se habría traducido en la creciente importancia del componente "no contributivo" de las políticas sociales en los últimos años. De allí que algunos autores hablen del pasaje de un sistema bismarckiano -centrado en la lógica contributiva-, a otro beveridgeano -apoyado en políticas "no contributivas"- (Filgueira, 2015).

7 Definimos al principal sostén del hogar como aquel miembro de la unidad doméstica cuyo ingreso es el mayor de entre todos los componentes del hogar. 


\section{LOS HOGARES Y SU PARTICIPACIÓN EN LA ESTRUCTURA ECONÓMICO-OCUPACIONAL}

Un conjunto de estudios sobre la inserción de la fuerza de trabajo en la estructura económico-ocupacional destaca que, si bien durante la post-convertibilidad se revirtió la tendencia incremental de la precariedad laboral iniciada en los ochenta y noventa, su estabilización en niveles históricamente elevados da cuenta de rasgos duraderos del mercado de trabajo argentino (Beccaria y Maurizio, 2012; Groisman, 2013; Salvia, Vera y Poy, 2015; Poy, 2017). Estos estudios son congruentes con aquellos que señalan que el estilo de crecimiento postconvertibilidad habría sido insuficiente para promover una mayor integración productiva y superar la heterogeneidad estructural (Gaggero, Schorr y Wainer, 2014; Piva, 2015).

El análisis de la inserción de los hogares en la estructura ocupacional a través de sus integrantes complementa esta perspectiva, al destacar las formas dominantes a través de las cuales las unidades domésticas participan en la distribución primaria del ingreso, lo que da cuenta de un determinante central del bienestar. En este sentido, el Cuadro 1 examina la participación de los hogares en la estructura económico-ocupacional según la posición de su principal sostén.

Cuadro 1. Distribución de hogares según posición económico-ocupacional del PSH. Hogares con PSH activo, total de aglomerados urbanos, 2003-2014. En porcentajes.

\begin{tabular}{|l|l|l|l|l|}
\hline & $\mathbf{2 0 0 3}$ & $\mathbf{2 0 0 7}$ & $\mathbf{2 0 1 1}$ & $\mathbf{2 0 1 4}$ \\
Sector formal privado & $\mathbf{3 9 , 2}$ & $\mathbf{4 6 , 3}$ & $\mathbf{4 7 , 7}$ & $\mathbf{4 6 , 2}$ \\
No asalariados y directivos & 5,2 & 5,6 & 5,4 & 4,9 \\
Asalariados registrados & 25,3 & 31,5 & 34,1 & 33,7 \\
Asalariados no registrados & 8,7 & 9,2 & 8,2 & 7,7 \\
Sector público & $\mathbf{1 5 , 0}$ & $\mathbf{1 6 , 5}$ & $\mathbf{1 7 , 9}$ & $\mathbf{1 8 , 2}$ \\
Empleados del sector público & 15,0 & 16,5 & 17,9 & 18,2 \\
Sector microinformal & $\mathbf{3 6 , 7}$ & $\mathbf{3 4 , 4}$ & $\mathbf{3 2 , 2}$ & $\mathbf{3 3 , 0}$ \\
No asalariados & 19,5 & 17,9 & 17,0 & 17,2 \\
Asalariados registrados & 3,7 & 5,3 & 5,0 & 5,3 \\
Asalariados no registrados & 13,5 & 11,2 & 10,2 & 10,5 \\
\hline Desoc. y benef. planes de & $\mathbf{9 , 1}$ & $\mathbf{2 , 8}$ & $\mathbf{2 , 1}$ & $\mathbf{2 , 6}$ \\
empleo & $\mathbf{1 0 0 , 0}$ & $\mathbf{1 0 0 , 0}$ & $\mathbf{1 0 0 , 0}$ & $\mathbf{1 0 0 , 0}$ \\
\hline Total &
\end{tabular}

Fuente: elaboración propia a partir de microdatos de la EPH-INDEC correspondientes al cuarto trimestre de cada año. 
Uno de los rasgos principales de los primeros años del ciclo postconvertibilidad (2003-2007) fue la elevada capacidad de absorción de fuerza de trabajo (Salvia, Vera y Poy, 2016). Esto se tradujo en una significativa reducción de los hogares cuyo PSH se encontraba desempleado o era beneficiario de un programa de empleo (que pasaron de $9,1 \%$ a $2,6 \%$ entre puntas del período). En paralelo, se incrementó la proporción de hogares que participaba en el sector formal privado $(39,2 \%$ a $46,3 \%)$, principalmente a través de posiciones asalariadas registradas $(25,3 \%$ a $31,5 \%)$, y en el sector público (15\% a 16,5\%). La proporción de hogares encabezados por un PSH en el sector microinformal se redujo muy levemente $(36,7 \%$ a $34,4 \%)$.

Luego de los años más intensos de crecimiento del ciclo postconvertibilidad, estas tendencias perdieron dinamismo y la participación sectorial económico-ocupacional de los hogares se mantuvo prácticamente inalterada (2007-2014). Aumentó la proporción de hogares cuyo PSH era asalariado registrado en el sector formal (31,5\% a $33,7 \%$ ) o empleado del sector público (16,5\% a 18,2\%). De esta forma, el proceso de recomposición verificado en los primeros años del ciclo post-reformas coexistió con una estabilización posterior. Hacia el final del período, más de 4 de cada 10 hogares participaban del sector microinformal de baja productividad, su principal proveedor disponía de una ocupación precaria en establecimientos del sector formal o estaban encabezados por un desocupado o beneficiario de un plan de empleo.

Este análisis puede complementarse con el de las posibilidades que tuvieron los hogares de participar en distintas posiciones económico-ocupacionales a través de sus diferentes miembros ocupados. Precisamente, se trata de una de las ventajas que tiene el abordaje de las unidades domésticas y que permite conocer mejor la evolución de las capacidades de reproducción de los hogares ${ }^{8}$

8 Desde el punto de vista metodológico, el análisis de la distribución de la fuerza de trabajo individual favorece las inferencias en torno al comportamiento de las estructuras productivas; en tanto que el análisis centrado en los hogares permite ganar conocimiento sobre los modos en que esa fuerza de trabajo efectivamente se reproduce (Torrado, 1992) 
Cuadro 2. Distribución de hogares según presencia de situaciones ocupacionales mixtas. Hogares con PSH activo, total de aglomerados urbanos, 2003-2014. En porcentajes.

\begin{tabular}{|c|c|c|c|c|}
\hline & 2003 & 2007 & 2011 & 2014 \\
\hline Hogares en sector formal(a) & 35,3 & 43,9 & 47,3 & 46,4 \\
\hline $\begin{array}{l}\text { PSH en sector formal } \\
\text { y ocupados en sector } \\
\text { microinformal }^{(b)}\end{array}$ & 19,0 & 18,9 & 18,4 & 18,0 \\
\hline $\begin{array}{l}\text { PSH en sector microinformal(b) } y \\
\text { ocupados en sector formal }\end{array}$ & 6,2 & 6,6 & 6,2 & 6,2 \\
\hline $\begin{array}{l}\text { Hogares en sector } \\
\text { microinformal(b) }^{(b)}\end{array}$ & 39,5 & 30,6 & 28,1 & 29,4 \\
\hline Total & 100,0 & 100,0 & 100,0 & 100,0 \\
\hline
\end{tabular}

Notas: (a) excluye desocupados y beneficiarios de planes de empleo / (b) Incluye desocupados y beneficiarios de planes de empleo. Fuente: elaboración propia a partir de microdatos de la EPHINDEC correspondientes al cuarto trimestre de cada año.

En este sentido, el Cuadro 2 permite destacar procesos de recomposición y desigualdades duraderas en la post-convertibilidad que refuerzan el análisis precedente. Por una parte, se ampliaron las chances de los hogares de participar en el sector formal, tanto público como privado: se incrementó la proporción de hogares que tenían todos sus ocupados en el sector formal $(35,3 \%$ a $46,4 \%)$ y se mantuvo la de aquellos que participaban en tal sector mediante alguno de sus ocupados. Por otra parte si bien se redujo la proporción de hogares que participaban exclusivamente en el sector microinformal (o con sus integrantes como desocupados y/o beneficiarios de planes de empleo), hacia 2014 29,4\% de los hogares con PSH activo se encontraban vinculados exclusivamente a este tipo de inserciones económico-ocupacionales.

Por último, cabe examinar lo ocurrido con las brechas de desigualdad provenientes de la participación económico-ocupacional de los hogares. Un primer aspecto que cabe destacar es que los hogares que participaban del sector formal privado a través de su PSH redujeron su brecha con respecto al ingreso per cápita familiar de fuente laboral promedio. Esta tendencia se explica, en parte, por una segunda cuestión emergente del análisis: los hogares cuyo PSH pertenecía al sector público se distanciaron progresiva y significativamente del promedio. Un tercer aspecto relevante remite a la relativa estabilidad que mantuvo la brecha de ingresos de los hogares que participaban en el sector microinformal con respecto al promedio y al deterioro relativo experimentado por los hogares cuyo PSH era asalariado no registrado del sector formal (Cuadro 3). 
Cuadro 3. Brecha del ingreso per cápita familiar real de fuente laboral según posición económico-ocupacional del PSH. Hogares con PSH ocupado(a), total de aglomerados urbanos, 2003-2014. Ingreso medio=1.

\begin{tabular}{|l|l|l|l|l|}
\hline & $\mathbf{2 0 0 3}$ & $\mathbf{2 0 0 7}$ & $\mathbf{2 0 1 1}$ & $\mathbf{2 0 1 4}$ \\
Sector formal privado & $\mathbf{1 , 2 5}$ & $\mathbf{1 , 1 5}$ & $\mathbf{1 , 0 9}$ & $\mathbf{1 , 1 0}$ \\
No asalariados y directivos & 2,54 & 2,15 & 1,90 & 2,00 \\
Asalariados registrados & 1,18 & 1,10 & 1,07 & 1,09 \\
Asalariados no registrados & 0,78 & 0,74 & 0,71 & 0,69 \\
Sector público & $\mathbf{1 , 1 7}$ & $\mathbf{1 , 2 2}$ & $\mathbf{1 , 3 6}$ & $\mathbf{1 , 3 6}$ \\
Empleados del sector público & 1,17 & 1,22 & 1,36 & 1,36 \\
Sector microinformal & $\mathbf{0 , 6 6}$ & $\mathbf{0 , 6 9}$ & $\mathbf{0 , 6 7}$ & $\mathbf{0 , 6 7}$ \\
No asalariados & 0,76 & 0,84 & 0,77 & 0,75 \\
Asalariados registrados & 0,88 & 0,80 & 0,85 & 0,82 \\
Asalariados no registrados & 0,47 & 0,41 & 0,43 & 0,48 \\
\hline Total & $\mathbf{1 , 0 0}$ & $\mathbf{1 , 0 0}$ & $\mathbf{1 , 0 0}$ & $\mathbf{1 , 0 0}$ \\
\hline
\end{tabular}

Nota: dado que se evalúan sólo los ingresos laborales netos de política social, se excluyó de este análisis a los hogares encabezados por desocupados 0 beneficiarios de programas de empleo. Véase el detalle en el Anexo Metodológico.

Fuente: elaboración propia a partir de microdatos de la EPH-INDEC correspondientes al cuarto trimestre de cada año.

De lo anterior, cabe concluir que si bien hubo una recomposición en la dinámica laboral durante la post-convertibilidad, en los últimos años del ciclo -con ritmos de crecimiento mucho menos intensos que los precedentes- se consolidó un núcleo de hogares (casi 4 de cada 10) que sólo participaba en las posiciones más desaventajadas de la estructura económico-ocupacional a través de sus miembros ocupados. Al mismo tiempo, la dinámica distributiva emergente de la participación en el mercado de trabajo tuvo algunos claroscuros, y aquellos hogares que participaban de posiciones en el sector microinformal se mantuvieron en una posición desventajosa durante el conjunto del período. Si estos fueron los principales rasgos de la capacidad de los hogares de participar en la distribución primaria del ingreso, ¿qué características tuvo la participación en la distribución secundaria? A responder este interrogante se dirige el próximo apartado.

\section{CAMBIOS EN LA MATRIZ DE INTERVENCIÓN SOCIAL DEL ESTADO EN EL CICLO POST-REFORMAS ESTRUCTURALES}

Diferentes investigaciones han constatado cambios en la forma de intervención social del Estado en el ciclo post reformas en relación con los años noventa (Curcio y Beccaria, 2013; Danani y Beccaria, 2013; Filgueira, 
2015). Las principales modificaciones pueden agruparse en tres ejes. En primer lugar, con respecto a las jubilaciones y pensiones, se verificó un aumento de la cobertura, debido a la implementación de "moratorias" y a la expansión del subsistema no contributivo ${ }^{10}$, y un aumento de la tasa de sustitución, por la recuperación del nivel de haberes ${ }^{11}$. En segundo lugar, se ampliaron las transferencias monetarias condicionadas, asociadas a la "lucha contra la pobreza", que habían adquirido un alcance masivo en la crisis de la convertibilidad (con el Plan Jefas y Jefes de Hogar, PJJHD). Por una parte, se extendieron los programas cuyo requisito era una contraprestación laboral (continuando así con líneas previas, como Trabajar o el PJJHD) o la participación en sistemas de capacitación (como el Seguro de Capacitación y Empleo y los programas de "ingreso social con trabajo", Argentina Trabaja y Ellas Hacen) $)^{12}$. Por otra parte, avanzaron los programas vinculados al cumplimiento de condicionalidades en capital educativo y humano, en especial de niños y adolescentes (como el Plan Familias para la Inclusión Social, la Asignación Universal por Hijo y por Embarazo o el Programa de Respaldo a Estudiantes de Argentina, PROGRESAR) ${ }^{13}$.

9 Entre las llamadas "contra reformas" (Danani y Beccaria, 2013) del sistema de previsión social, se destacan la "moratoria previsional" que permitió acceder a un haber jubilatorio a quienes tenían edad para jubilarse pero no cumplían con la exigencia del número de años requeridos (Decreto 1454, del año 2005); y, en noviembre de 2008, la Ley 26.425 que derogó el régimen de capitalización y creó el Sistema Integrado Previsional Argentina (SIPA).

10 Hasta el año 2003 existía una restricción cuantitativa del número de pensiones no contributivas que el Estado podía entregar. Hasta entonces, sólo podían darse altas cuando se registraba una baja. La eliminación de ese "cupo" permitió la expansión de este tipo de transferencias económicas.

11 Tras la crisis de 2001-2002, el Gobierno lanzó una serie de medidas tendientes a incrementar la jubilación mínima. Así, entre 2003 y 2007 ésta aumentó 250\% en términos nominales y $80 \%$ en términos reales. Esto tendió a alterar la "pirámide" previsional (Rofman y Oliveri, 2012).

12 Con posterioridad al PJJHD, algunos beneficiarios pasaron al Seguro de Capacitación y Empleo, que se inscribió en la lógica de promoción de la "empleabilidad". Por su parte, el programa Argentina Trabaja procuró articular la lógica del trabajo cooperativo con una transferencia de ingreso. No obstante, como señalan Arcidiácono, Kalpschtrej y Bermúdez (2014: 353), si bien procuró aplicar un formato de economía social, el programa siguió ligado a un esquema de política asistencial. En este sentido, Hopp (2016) da cuenta de la elevada desprotección social de los trabajadores del programa, lo que evidencia sus limitaciones para desenvolver formas alternativas de empleo en el marco de la economía social.

13 A partir del año 2009, el Estado argentino creó la Asignación Universal por Hijo para Protección Social, dirigida a los hijos/as de trabajadores informales, en el servicio doméstico, desocupados o monotributistas sociales. Implica condicionalidades de control sanitario y asistencia a la escuela. En 2011 se extendió esta asignación a las mujeres embarazadas (Asignación Universal por Embarazo). Por su parte, en 2014 se puso en marcha el PROGRESAR dirigido a estudiantes de 18 a 24 años. 
En tercer lugar, el régimen de asignaciones familiares tuvo una evolución errática pese al aumento del empleo e incluso llegó a retraer su nivel de cobertura en términos absolutos debido al atraso en la actualización de los topes que permitían acceder al beneficio como resultado de la inflación (CIFRA, 2012; MTEYSS, 2008, 2009, 2012).

La diferente evolución de estos componentes del sistema de políticas sociales se plasmó en la proporción de hogares cubiertos por los mismos (Cuadro 4). En primer término, se destacó la retracción de la proporción de hogares que recibían programas de empleo y la estabilidad de la cobertura por seguro de desempleo. En segundo término, el sistema de jubilaciones y pensiones tuvo una expansión significativa en términos de cobertura entre 2003 y 2007 (asociada a la primera "moratoria”, de 2005) y una nueva expansión entre ese año y 2011 (vinculada, también, con el crecimiento de las pensiones no contributivas). En tercer lugar, las asignaciones familiares incrementaron su cobertura entre 2003 y 2007, declinaron por falta de actualización de topes por inflación hacia 2011 y, como resultado del cambio en éstos, volvió a aumentar la cobertura en 2014. Finalmente, la cobertura de transferencias monetarias directas se incrementó entre 2003 y 2007 (una parte de lo cual tiene que ver con el pasaje de PJJHD -que era un programa de empleo-a este tipo de transferencias directas) y, especialmente, entre ese año y 2011, a partir del lanzamiento de la Asignación Universal por Hijo en 2009.

Cuadro 4. Cobertura del sistema de políticas sociales según tipo de instrumento(a). Hogares con PSH activo, total de aglomerados urbanos, 2003-2014. En porcentajes.

\begin{tabular}{|l|l|l|l|l|}
\hline & $\mathbf{2 0 0 3}$ & $\mathbf{2 0 0 7}$ & $\mathbf{2 0 1 1}$ & $\mathbf{2 0 1 4}$ \\
Programas de empleo & 10,3 & 2,8 & 1,0 & 1,4 \\
Seguro de desempleo & 0,6 & 0,5 & 0,5 & 0,4 \\
Jubilaciones / Pensiones & 13,5 & 17,0 & 19,9 & 20,3 \\
Asignaciones familiares & 16,2 & 21,5 & 14,7 & 18,6 \\
Transferencias monetarias directas (inc. & 3,2 & 6,4 & 14,4 & 14,3 \\
AUH) & $\mathbf{4 0 , 5}$ & $\mathbf{4 4 , 3}$ & $\mathbf{4 4 , 7}$ & $\mathbf{4 8 , 9}$ \\
\hline Total $^{(\mathbf{b})}$ & & & \\
\hline
\end{tabular}

Notas: (a) Sobre el modo en que fueron captadas e imputadas al ingreso total familiar, véase el Anexo Metodológico/ (b) Es el porcentaje de hogares que recibe al menos un tipo de transferencia sobre el total de hogares; por consiguiente, no surge de la suma de las demás categorías del Cuadro.

Fuente: elaboración propia a partir de microdatos de la EPH-INDEC correspondientes al cuarto trimestre de cada año.

En general, las investigaciones distributivas analizan el rol de las políticas sociales de manera agregada, sin examinar las diferentes posi- 
ciones económico-ocupacionales en que participan los hogares que acceden a dichos recursos. Aquí interesa preguntarse: ¿qué papel desempeñaron tanto a nivel general como entre los distintos grupos económico-ocupacionales de hogares anteriormente descriptos los distintos instrumentos de política social?

El Cuadro 5 indica que los cambios consignados en la forma de intervención social del Estado se tradujeron en una expansión de la población de hogares cubierta por estos instrumentos. Entre 2003 y 2014, la cobertura pasó de 40,5\% a 48,9\% de las unidades domésticas. Esta evolución reconoce dos momentos: una primera expansión entre 2003 y 2007 (cuando alcanzó 44,3\%) y una segunda expansión, entre 2007 y 2014 (tras la cual llegó a 48,9\%). Pero esta pauta distó de ser homogénea: si bien creció la cobertura entre los hogares cuyo PSH pertenecía al sector formal privado (al pasar de 38,6\% a 47,6\%), el incremento fue mucho más intenso entre aquellos cuyo PSH pertenecía al sector microinformal $(30,2 \%$ a $51,2 \%)$ y tuvo un recorrido inverso entre aquellos hogares con PSH en el sector público (de 53,6\% a $47,4 \%)^{14}$.

14 También se modificó la cobertura entre aquellos hogares cuyo PSH se encontraba desocupado o era beneficiario de un programa de empleo, pero en un sentido distinto al verificado en el resto de los hogares. La reducción de aquellos cubiertos por instrumentos de política social (de 68,7\% a 54,8\%) es indicativa de un cambio de composición de este grupo (Cuadro 6.2). Al respecto, podemos conjeturar que se transitó de situaciones de desempleo consolidado durante la crisis de la convertibilidad hacia un escenario de desempleo friccional, lo que implica una mayor heterogeneidad de este grupo de hogares y, en consecuencia, del tipo de cobertura al que accedían. 
Cuadro 5. Cobertura del sistema de políticas sociales según posición económico-ocupacional del PSH. Hogares con PSH activo, total de aglomerados urbanos, 2003-2014.

En porcentajes.

\begin{tabular}{|l|l|l|l|l|}
\hline & $\mathbf{2 0 0 3}$ & $\mathbf{2 0 0 7}$ & $\mathbf{2 0 1 1}$ & $\mathbf{2 0 1 4}$ \\
Sector formal privado & $\mathbf{3 8 , 6}$ & $\mathbf{4 3 , 5}$ & $\mathbf{4 1 , 6}$ & $\mathbf{4 7 , 6}$ \\
No asalariados y directivos & 24,9 & 23,2 & 29,4 & 31,6 \\
Asalariados registrados & 44,7 & 49,6 & 42,0 & 49,0 \\
Asalariados no registrados & 29,1 & 35,2 & 47,7 & 51,6 \\
Sector público & $\mathbf{5 3 , 6}$ & $\mathbf{5 8 , 1}$ & $\mathbf{4 3 , 3}$ & $\mathbf{4 7 , 4}$ \\
Empleados del sector público & 53,6 & 58,1 & 43,3 & 47,4 \\
Sector microinformal & $\mathbf{3 0 , 2}$ & $\mathbf{3 7 , 8}$ & $\mathbf{4 9 , 4}$ & $\mathbf{5 1 , 2}$ \\
No asalariados & 27,6 & 32,0 & 45,6 & 44,9 \\
Asalariados registrados & 42,8 & 51,3 & 45,1 & 48,4 \\
Asalariados no registrados & 30,5 & 40,7 & 58,1 & 62,9 \\
\hline Desoc. y benef. planes de & $\mathbf{6 8 , 7}$ & $\mathbf{5 4 , 4}$ & $\mathbf{5 5 , 4}$ & $\mathbf{5 4 , 8}$ \\
empleo & $\mathbf{4 0 , 5}$ & $\mathbf{4 4 , 3}$ & $\mathbf{4 4 , 7}$ & $\mathbf{4 8 , 9}$ \\
\hline Total &
\end{tabular}

Fuente: elaboración propia a partir de microdatos de la EPH-INDEC correspondientes al cuarto trimestre de cada año.

Esta expansión cuantitativa de la cobertura de los sistemas de políticas sociales que transfieren ingresos a los hogares pareciera implicar una tendencia a la homogeneización. Sin embargo, este proceso oculta dinámicas diferentes, en tanto las relaciones de mercado que rigen el acceso a estos instrumentos tienen un alcance desigual en los distintos estratos económico-ocupacionales. Al respecto, el Gráfico 1 da cuenta de que el aumento cuantitativo de la cobertura corrió parejo con una heterogeneización del tipo de instrumentos al que acceden los hogares. 
Gráfico 1. Distribución de hogares que reciben políticas sociales por tipo de instrumento según posición sectorial económico-ocupacional del PSH. Hogares con PSH activo, total de aglomerados urbanos, 2003-2014. En porcentajes.
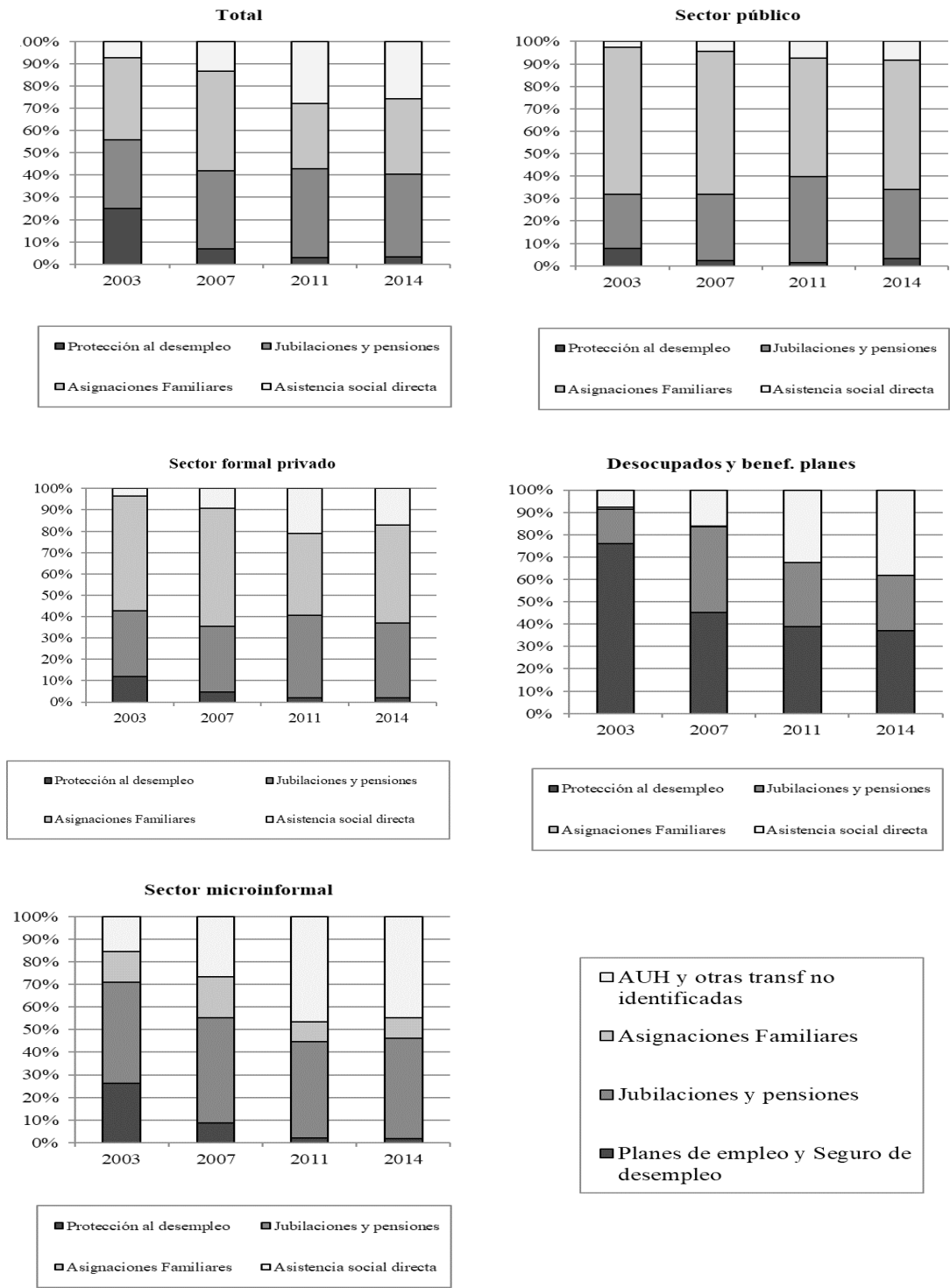

$\square$ AUH y otras transf no
identificadas
$\square$ Asignaciones Familiares
$\square$ Jubilaciones y pensiones
$\square$ Planes de empleo y Seguro de
desempleo

Fuente: elaboración propia a partir de microdatos de la EPH-INDEC correspondientes al cuarto trimestre de cada año. 
Entre aquellos cuyo PSH estaba ocupado en el sector formal público o privado, fueron dominantes las transferencias por salario familiar y por jubilaciones y pensiones, teniendo un papel menor las transferencias monetarias condicionadas o los programas sociales de empleo ${ }^{15}$. En cambio, entre los hogares encabezados por un trabajador del sector microinformal o por un desempleado, adquirieron significación, además de los ingresos por jubilaciones y pensiones, las transferencias directas (como la AUH) y los programas de empleo.

\section{MERCADO DE TRABAJO, POLÍTICAS SOCIALES Y CAMBIOS EN LAS CONDICIONES DE VIDA FAMILIARES EN EL CICLO POST-REFORMAS ESTRUCTURALES}

El propósito de este apartado es analizar articuladamente qué papel desempeñaron el mercado de trabajo y las formas de intervención estatal por medio de políticas sociales sobre el cambio en las condiciones de vida familiares. El análisis se enriquece si se examinan no sólo estos procesos a nivel agregado, sino entre diferentes grupos económico-ocupacionales. Al describir articuladamente procesos vinculados con la distribución primaria y secundaria, se puede echar luz sobre transformaciones en los patrones de reproducción social de distintos grupos de hogares (Salvia, 2012).

Con el propósito de conocer la incidencia y el sentido de los diferentes componentes que modificaron las condiciones de vida, se descomponen los cambios en el ingreso per cápita familiar (IPCF). Este modelo de descomposición es una adaptación de la metodología que Cortés (1995) aplicó a la distribución del ingreso de México. Habitualmente, los economistas descomponen la desigualdad distributiva -empleando algún índice o medida sintética como el coeficiente de Gini o el de Theil (Bourguignon y Ferreira, 2004)- o la tasa de pobreza -como en el popular método de Datt y Ravallion (1992)-. Desde una perspectiva complementaria, interesa incluir una descomposición del crecimiento del ingreso per cápita entre dos períodos de tiempo ${ }^{16}$.

El ingreso per cápita familiar de un grupo de hogares $g$ puede ser escrito del siguiente modo:

$$
\mathrm{IPCF}_{g}=\mathrm{Y} / \mathrm{PER}_{g} \mathrm{NPER}_{g} \mathrm{NCOMP}_{g}^{-1}
$$

$15 \mathrm{El}$ incremento de la participación de la transferencias monetarias directas en los años 2011 y 2014 entre estos hogares puede atribuirse a la presencia de asalariados no registrados en el sector formal privado.

16 Además de Cortés (1995) existen otros antecedentes que han aplicado este tipo de enfoque. En Argentina, Donza (2015) aplicó este método y en Reino Unido Brewer y Wren-Lewis (2015) plantearon un abordaje similar. 
Es decir que el IPCF es el resultado del ingreso medio por perceptor del hogar (Y/PER), el número de perceptores del hogar (NPER) y la inversa del número de componentes del hogar. Como demuestra Cortés (1995), cuando estos componentes varían a tasas $r, p$, y $e$, respectivamente, el cambio del ingreso per cápita familiar puede escribirse del siguiente modo:

$$
\Delta \mathrm{IPCF}_{\mathrm{t} 1, \mathrm{t} 0}=\mathrm{IPCF}_{\mathrm{t} 0}(\mathrm{r}+\mathrm{p}+\mathrm{e}+\mathrm{rp}+\mathrm{re}+\mathrm{pe}+\mathrm{rpe})(2)
$$

Denotando con $r, p$, ye las tasas de variación del ingreso por perceptor, el número de perceptores de ingresos por hogar y la inversa del número de componentes, respectivamente; y siendo los demás términos las interacciones de primer, segundo y tercer orden entre ellos. Siguiendo la lógica precedente, pueden incorporarse diferentes $k$ fuentes de ingreso para describir los cambios en el IPCF, de modo que la ecuación (1) pasa a tener la siguiente estructura:

$$
\mathrm{IPCF}_{g}={\mathrm{Y} / \mathrm{PER}_{g, k 1}}^{\mathrm{NPER}_{g, k 1}} \mathrm{NCOMP}_{g}^{-1}+(\ldots)+{\mathrm{Y} / \mathrm{PER}_{g, \mathrm{kn}}} \mathrm{NPER}_{g, k n} \mathrm{NCOMP}_{g}^{-1}
$$

Y el cambio en el IPCF entre dos momentos $t_{0} \mathrm{y} t_{1}$ puede escribirse del siguiente modo:

$$
\begin{aligned}
& \Delta \mathrm{IPCF}_{g 11, t 0}=\operatorname{IPCF}_{g \mathrm{k} 1, t 0}\left(\mathrm{r}_{\mathrm{k} 1}+\mathrm{p}_{\mathrm{k} 1}+\mathrm{e}+\mathrm{r}_{\mathrm{k} 1} \mathrm{p}_{\mathrm{k} 1}+\mathrm{r}_{\mathrm{k} 1} \mathrm{e}+\mathrm{p}_{\mathrm{k} 1} \mathrm{e}+\mathrm{r}_{\mathrm{k} 1} \mathrm{p}_{\mathrm{k} 1} \mathrm{e}\right)+(\ldots)+ \\
& \mathrm{IPCF}_{g k n, t 0}\left(\mathrm{r}_{\mathrm{k} n}+\mathrm{p}_{\mathrm{k} n}+\mathrm{e}+\mathrm{r}_{\mathrm{kn} n} \mathrm{p}_{\mathrm{k} n}+\mathrm{r}_{\mathrm{kn} n} \mathrm{e}+\mathrm{p}_{\mathrm{k} n} \mathrm{e}+\mathrm{r}_{\mathrm{k} n} \mathrm{p}_{\mathrm{k} n} \mathrm{e}\right)
\end{aligned}
$$

En la ecuación (4), los términos $r$ y $p$ constituyen las tasas de variación del ingreso por perceptor y del número de perceptores por hogar de cada una de las $k$ fuentes consideradas; y el término $e$ recoge el cambio en el tamaño del hogar ponderado por la incidencia de cada $k$ fuente en el ingreso.

Esta ecuación permite contestar los siguientes interrogantes: ¿qué papel tuvieron las fuentes laborales, las políticas sociales y otros ingresos no laborales en los cambios en las condiciones de vida? ¿Qué factores tuvieron más incidencia y qué diferencias se advierten entre distintos grupos según su posición económico-ocupacional? Para llevar adelante este análisis, el foco está puesto en dos períodos diferenciados del régimen de crecimiento reciente en la Argentina: la etapa de alto crecimiento en la post-convertibilidad (2003-2007) y el ciclo de ralentización y crisis del modelo post-reformas (2007-2014) ${ }^{17}$.

17 Para simplificar la exposición, los Cuadros 6 y 7 sólo exponen la contribución de cada fuente al cambio en el ingreso. El papel desempeñado por el ingreso medio 


\section{(I) “CICLO DE ORO” DEL PERÍODO POST-REFORMAS ESTRUCTURALES (2003-2007)}

La devaluación que siguió a la salida del régimen de convertibilidad implicó un veloz e intenso proceso de reducción de los ingresos familiares, que ya venían deteriorados por la recesión que caracterizó a los últimos años del programa de ajuste estructural (Salvia, 2012). El Cuadro 6 permite entender los distintos factores económicos subyacentes a la recomposición de las condiciones de vida familiares durante este período.

El ingreso per cápita familiar creció sostenida y significativamente a nivel general en todo el período 2003-2007 (43,4\%). El papel principal lo desempeñaron las fuentes laborales $(38,8 \%)$, mientras que los ingresos provenientes de políticas sociales y de otras fuentes no laborales de los hogares (ingresos por transferencias entre privados, cuotas alimentarias, rentas y dividendos, alquileres, etc.) tuvieron un rol mucho menor aunque positivo $(2,4 \%$ y $2,2 \%$, respectivamente) en el cambio. Es decir que, más allá de la expansión constatada a nivel general en el sistema de políticas sociales durante esta etapa, el principal motor del cambio en las condiciones de vida familiares estuvo constituido centralmente por procesos asociados a la dinámica económico-ocupacional.

Entre los hogares que participaban del sector formal privado a través de su PSH, el ritmo de crecimiento del ingreso per cápita familiar estuvo por debajo del promedio general, lo que se debió al papel de los hogares cuyo PSH era no asalariado o directivo. Los hogares encabezados por un PSH empleado del sector público tuvieron un ritmo de recomposición muy superior al promedio, y otro tanto sucedió, en esta instancia, con aquellos encabezados por no asalariados del sector microinformal. En cambio, entre los hogares cuyo PSH era asalariado del sector informal, la mejora en las condiciones de vida fue menos intensa, y estuvo próxima a lo ocurrido entre los hogares cuyo PSH era asalariado del sector formal.

por perceptor y por el número de perceptores de cada fuente, si bien se comenta, se encuentra detallado en los Cuadros A1 y A2 del Anexo Estadístico. 
Cuadro 6. Cambio en el ingreso per cápita familiar y efecto de las diferentes fuentes de ingreso, según posición económico-ocupacional del PSH. Hogares con PSH activo, total de aglomerados urbanos, 2003-2007. En variación porcentual.

\begin{tabular}{|l|llll|}
\hline & Var. IPCF & $\begin{array}{l}\text { Ingresos } \\
\text { laborales }\end{array}$ & $\begin{array}{l}\text { Ingresos } \\
\text { de políticas } \\
\text { sociales }\end{array}$ & $\begin{array}{l}\text { Otros } \\
\text { ingresos no } \\
\text { laborales }\end{array}$ \\
Sector formal privado & $\mathbf{2 4 , 3}$ & $\mathbf{2 1 , 0}$ & $\mathbf{1 , 6}$ & $\mathbf{1 , 7}$ \\
No asalariados y directivos & 16,0 & 12,8 & $-1,5$ & 4,6 \\
Asalariados registrados & 27,4 & 24,2 & 2,5 & 0,7 \\
Asalariados no registrados & 29,5 & 24,4 & 3,2 & 1,9 \\
Sector público & $\mathbf{4 0 , 4}$ & $\mathbf{3 5 , 6}$ & $\mathbf{3 , 3}$ & $\mathbf{1 , 4}$ \\
Empleados del sector público & 40,4 & 35,6 & 3,3 & 1,4 \\
Sector microinformal & $\mathbf{3 9 , 9}$ & $\mathbf{3 4 , 8}$ & $\mathbf{3 , 2}$ & $\mathbf{1 , 9}$ \\
No asalariados & 45,0 & 41,6 & 2,0 & 1,4 \\
Asalariados registrados & 24,9 & 19,3 & 4,4 & $\mathbf{1 , 1}$ \\
Asalariados no registrados & 23,7 & 15,5 & 4,4 & 3,8 \\
\hline Desoc. y benef. planes de & $\mathbf{1 4 7 , 9}$ & $\mathbf{3 5 , 6}$ & $\mathbf{2 9 , 8}$ & $\mathbf{8 2 , 5}$ \\
empleo & & $\mathbf{3 3 , 4}$ & $\mathbf{2 , 4}$ & $\mathbf{2 , 2}$ \\
\hline Total &
\end{tabular}

Fuente: elaboración propia a partir de microdatos de la EPH-INDEC correspondientes al cuarto trimestre de cada año.

Si se consideran los factores sociales y demográficos subyacentes al cambio en las condiciones de vida familiares, se observa el papel predominante que jugaron, para el conjunto de los hogares urbanos, el aumento del ingreso de los ocupados como el promedio de ocupados por hogar (Cuadro A1). En contraste, fue marginal la contribución que hizo el aumento del ingreso por perceptor de políticas sociales a la mejora del ingreso familiar, y algo más importante el aumento en el número promedio de perceptores de dicha fuente.

Es decir que, más allá de las diferencias observadas en los niveles de crecimiento del ingreso per cápita familiar entre los hogares de distintas posiciones económico-ocupacionales, se mantuvo un patrón en el cual el factor explicativo central correspondió a los procesos vinculados con el mercado de trabajo. Si bien los ingresos por políticas sociales contribuyeron en todos los casos (a excepción de los hogares encabezados por no asalariados del sector formal) positivamente a esta recomposición, su papel fue reducido para explicar cambios en las condiciones de vida familiares. 


\section{(II) CICLO DE RALENTIZACIÓN Y CRISIS DEL MODELO POST-CONVERTIBILIDAD (2007-2014)}

El segundo ciclo del período post-reformas estructurales estuvo caracterizado por un ritmo más lento y errático de crecimiento económico que el primer ciclo analizado. En este sentido, la mejora de las condiciones de vida no mantuvo una tendencia lineal, a la vez que se observaron diferencias significativas con el período precedente (Cuadro 7).

Este período contrasta en un sentido cuantitativo y cualitativo con el anterior. En un sentido cuantitativo, el crecimiento del ingreso per cápita familiar fue significativamente más bajo que en el período precedente $(4,9 \%)$, que además había sido más breve. Desde el punto de vista cualitativo, el aumento originado en fuentes laborales continuó siendo relevante para entender este cambio $(3,5 \%)$, pero los ingresos de políticas sociales adquirieron un papel mucho más decisivo $(2,1 \%)$. En contrapartida, los ingresos provenientes de otras fuentes no laborales jugaron un papel negativo en las capacidades de reproducción $(-0,8 \%)$. De este modo, en el contexto de mayor inflación y pérdida de dinamismo del mercado de trabajo, se alteró la importancia relativa de las distintas fuentes de que disponen los hogares en el acceso al bienestar.

Entre los hogares que participaban del sector privado formal a través de su PSH, el ingreso familiar creció muy por debajo del promedio, pero escondiendo tres comportamientos distintos. Aumentó entre los hogares cuyo PSH tenía un empleo registrado, se redujo entre los hogares cuyo PSH era no asalariado o directivo, y no tuvo cambios en los hogares cuyo PSH era asalariado no registrado. Los hogares cuyo PSH era empleado del sector público tuvieron -al igual que en el período 2003-2007- un incremento de sus ingresos muy por encima del promedio general. Finalmente, entre los hogares cuyo PSH pertenecía al sector microinformal, el ingreso familiar subió cerca del promedio, pero en tanto casi no varió entre aquellos cuyo PSH era no asalariado, se incrementó entre los hogares cuyo PSH era asalariado, tanto registrado como no registrado ${ }^{18}$.

18 Los hogares encabezados por un PSH asalariado no registrado parecen haber recuperado ingresos, en esta segunda etapa del ciclo, en tanto habían sido los más rezagados en la primera etapa. Si bien aquí no examinamos niveles (estos hogares persistieron siendo los que se encontraban en la peor situación relativa en la distribución), una hipótesis sobre este comportamiento anómalo podría hallarse en el papel regulador que empezó a tener, por una parte, la instalación de ingresos normativos para el empleo en el servicio doméstico y, por otra parte, el salario mínimo vital y móvil, que si bien institucionalmente regula la economía registrada, tiene efectos derivados sobre el empleo no registrado de bajos ingresos. 
Cuadro 7. Cambio en el ingreso per cápita familiar y efecto de las diferentes fuentes de ingreso, según posición económico-ocupacional del PSH. Hogares con PSH activo, total de aglomerados urbanos, 2007-2014. En variación porcentual.

\begin{tabular}{|l|llll|}
\hline & Var. IPCF & $\begin{array}{l}\text { Ingresos } \\
\text { laborales }\end{array}$ & $\begin{array}{l}\text { Ingresos } \\
\text { de políticas } \\
\text { sociales }\end{array}$ & $\begin{array}{l}\text { Otros } \\
\text { ingresos no } \\
\text { laborales }\end{array}$ \\
Sector formal privado & $\mathbf{0 , 4}$ & $\mathbf{0 , 1}$ & $\mathbf{1 , 5}$ & $-\mathbf{1 , 2}$ \\
No asalariados y directivos & $-3,2$ & $-3,0$ & 3,3 & $-3,5$ \\
Asalariados registrados & 3,1 & 2,6 & 0,8 & $-0,3$ \\
Asalariados no registrados & $-0,3$ & $-2,2$ & 3,5 & $-1,5$ \\
Sector público & $\mathbf{1 3 , 1}$ & $\mathbf{1 4 , 5}$ & $\mathbf{- 0 , 7}$ & $\mathbf{- 0 , 7}$ \\
Empleados del sector público & 13,1 & 14,5 & $-0,7$ & $-0,7$ \\
Sector microinformal & $\mathbf{6 , 7}$ & $\mathbf{0 , 9}$ & $\mathbf{5 , 8}$ & $\mathbf{0 , 0}$ \\
No asalariados & $-0,1$ & $-5,7$ & 5,9 & $-0,3$ \\
Asalariados registrados & 9,8 & 6,2 & 2,3 & 1,2 \\
Asalariados no registrados & 27,8 & 19,1 & 8,7 & $-0,1$ \\
\hline Desoc. y benef. planes de & $\mathbf{6 , 3}$ & $\mathbf{3 , 5}$ & $\mathbf{2 , 9}$ & $\mathbf{0 , 0}$ \\
empleo & $\mathbf{4 , 9}$ & $\mathbf{3 , 5}$ & $\mathbf{2 , 1}$ & $\mathbf{- 0 , 8}$ \\
\hline Total &
\end{tabular}

Fuente: elaboración propia a partir de microdatos de la EPH-INDEC correspondientes al cuarto trimestre de cada año.

La relevancia de los ingresos provenientes de políticas sociales en las condiciones de vida familiares no fue similar entre diferentes grupos de hogares. Pasaron a jugar un papel central para "compensar" la reducción de ingresos laborales entre los hogares cuyo PSH era asalariado no registrado del sector formal y entre aquellos cuyo PSH era no asalariado del sector microinformal. Paralelamente, cumplieron un papel importante para "complementar" ingresos entre los hogares cuyo PSH era asalariados registrado o no registrado del sector microinformal, si bien en estos casos también aumentaron los ingresos de fuentes laborales ${ }^{19}$.

Los distintos mecanismos que explican esta performance también modificaron su relevancia (Cuadro A2). Si bien nuevamente el aumento de los ingresos por perceptor laboral tuvo un papel positivo en la mejora de las capacidades de reproducción (2,3\%), se redujo el promedio de ocupados por hogar, lo que condicionó negativamente el

19 Los ingresos provenientes de políticas sociales también parecen haber jugado un papel importante entre los no asalariados y directivos del sector formal privado. En este punto, un papel clave lo desempeñaron las jubilaciones y pensiones. 
bienestar $(-1,6 \%)$. En cambio, se verificó tanto un aumento del ingreso por perceptor de políticas sociales como un incremento del número promedio de perceptores por hogar de este tipo de ingreso, lo que aportó a mejorar de las condiciones de vida $(0,4 \%$ y $1,3 \%$, respectivamente).

\section{RESUMEN DE HALLAZGOS Y REFLEXIONES FINALES}

Este capítulo se propuso articular el estudio de la estructura social del trabajo con el análisis de las políticas sociales, desde una perspectiva centrada en los cambios en las condiciones de vida familiares. El tipo de análisis presentado permitió caracterizar los modos en que se han relacionado la heterogeneidad estructural del mercado laboral y las formas de intervención estatal por medio de políticas sociales en la recomposición de las condiciones de vida. De esta manera, el capítulo contribuyó a describir los cambios sucedidos en el patrón distributivo del ingreso familiar durante el ciclo post-reformas.

En primer término, el capítulo exhibió un proceso de recomposición del mercado laboral que incidió en las posibilidades de los hogares de participar en el sector formal público y privado y de disponer de empleos registrados. Este proceso tuvo dos características centrales: por una parte, se concentró en los primeros años del período y, por otra parte, fue limitado en su alcance, en tanto que más de 4 de cada 10 hogares eran encabezados, al término del período, por un ocupado en el sector microinformal, por un trabajador no registrado, por un beneficiario de un programa de empleo o por un desocupado. Se trata de un aspecto significativo en tanto que, como se señaló, no sólo fueron limitadas las chances de los hogares de "combinar" distintas formas de inserción económico-ocupacional, sino que las brechas de ingreso familiar de fuente laboral se mantuvieron relativamente estables. En síntesis, la recomposición del mercado de trabajo coexistió con desigualdades estructurales en el acceso al bienestar a partir de la participación en la distribución primaria del ingreso.

En segundo lugar, el capítulo evidenció el papel activo y significativo que pasó a tener, en términos de cobertura, un conjunto de políticas sociales que implican transferencias económicas a los hogares y desempeñan un rol importante en la distribución secundaria del ingreso. Por una parte, se pudo constatar una tendencia a la homogeneización de los niveles de cobertura de los hogares con independencia de su posición en la estructura económico-ocupacional. Este proceso tuvo que ver, principalmente, con la expansión de la cobertura sobre los hogares cuyo PSH se insertaba en el sector microinformal o era asalariado no registrado. Por otra parte, esta homogeneización corrió pareja con una persistente heterogeneidad del tipo de instrumentos a 
los que acceden los hogares, que reproduce la propia heterogeneidad del sistema económico-ocupacional.

En este marco, una descomposición del cambio en el ingreso per cápita familiar permitió aproximarse al papel que jugaron los cambios en el mercado de trabajo y en las políticas sociales sobre las condiciones de vida. El análisis simultáneo de los procesos asociados al mercado laboral y a las políticas sociales permitió constatar una serie de cambios en los modos de reproducción de los hogares durante el ciclo post-reformas. En el período 2003-2007, el eje del cambio en las condiciones de vida estuvo en el mercado de trabajo y se canalizó a nivel de los hogares principalmente a través de una mejora del ingreso promedio por ocupado y, secundariamente, por un aumento del número promedio de ocupados por hogar. Un aspecto singular de esta evolución fue que, si bien reconoció ritmos y niveles diferentes, tuvo características similares entre los distintos grupos económico-ocupacionales. En contraste, en el período 2007-2014, los ingresos provenientes de la intervención social del Estado ganaron relevancia para explicar los cambios en las condiciones de vida. En particular, entre los hogares cuyo PSH era asalariado no registrado en el sector formal o no asalariado del sector microinformal, sostuvieron las condiciones de vida familiares en un contexto adverso para los ingresos laborales. En menor grado, también jugaron un papel relevante en complementar ingresos entre aquellos hogares cuyo PSH era asalariado del sector menos estructurado. Es decir que, en un contexto de menor dinamismo del modelo económico post-reformas y persistencia de exclusiones estructurales, la intervención estatal pasó a ser un elemento clave para las condiciones de vida familiares.

A modo de reflexión final, cabe preguntarse por la efectiva capacidad que pueden alcanzar los sistemas de política social para promover convergencia social en términos de condiciones de vida, en el marco de persistentes desigualdades estructurales que provienen de la estructura económico-ocupacional. Este capítulo ha mostrado que el principal papel de estos instrumentos ha sido el de acompañar y eventualmente compensar en el ciclo de menor dinamismo del mercado de trabajo. Aún no sabemos en qué grado estas intervenciones operaron sobre indicadores del bienestar como la pobreza monetaria. Todo lo cual conduce a reflexionar no sólo en torno a la importancia de los mecanismos de aseguramiento de ingresos no fundados en la participación laboral, sino también sobre el papel decisivo que adquiere la regulación laboral, y el aumento de los ingresos y de capacidades productivas en el sector menos estructurado del entramado económicoocupacional. 


\section{REFERENCIAS BIBLIOGRÁFICAS}

Andrenacci, L. (2012). From Developmentalism to Inclusionism. On the Transformation of Latin American Welfare Regimes in the Early 21st Century. Journal für Entwicklungspolitik, 23 (1), 35-57.

Arcidiácono, P., Kalpschtrej, K. y Bermúdez, A. (2014). ¿Transferencias de ingresos, cooperativismo o trabajo asalariado? El Programa Argentina Trabaja. Revista Trabajo y Sociedad, 22, 341-356.

Barba Solano, C. (2007). América Latina: regímenes de bienestar en transición durante los años noventa. Caderno CRH, 20 (50), 197-211.

Bárcena, A. y Prado, A. (2016). El imperativo de la igualdad. Por un desarrollo sostenible en América Latina y el Caribe. Buenos Aires: Siglo XXI y CEPAL.

Beccaria, L. y Groisman, F. (2009). Informalidad y pobreza: una relación compleja. En L. Beccaria y F. Groisman (eds.), Argentina desigual (pp. 95-155). Los Polvorines: UNGS-Prometeo.

Beccaria, L. y Maurizio, R. (2012). Reversión y continuidades bajo dos regímenes macroeconómicos diferentes. Mercado de trabajo e ingresos en Argentina 1990-2010. Desarrollo Económico, 52 (206), 205-228.

Beccaria, L; Carpio, J. y Orsatti, A. (2000). Argentina: informalidad laboral en el nuevo modelo económico. En J. Carpio, E. Klein, e I. Novacovsky (comps.), Informalidad y exclusión social (pp. 139160). Buenos Aires: Fondo de Cultura Económica-SIEMPROOIT.

Benza, G. (2016). La estructura de clases argentina durante la década 2003-2013. En G. Kessler (comp.), La sociedad argentina hoy. Radiografía de una nueva estructura (pp. 111-139). Buenos Aires: Siglo XXI-Fundación OSDE.

Bourguignon, F. y Ferreira, F. (2004). Decomposing Changes in the Distribution of Households Incomes: Methodological Aspects. En F. Bourguignon, F. Ferreira y N. Lustig (eds), The Microeconomic of Income Distribution Dynamics in East Asia and Latin America (pp. 17-46). Washington D.C: World Bank - Oxford University Press.

Brewer, M. y L. Wren-Lewis (2011). Why did Britain's households get richer? Decomposing UK household income growth between 1968 and 2008-09 (Briefing Note $N^{\circ}$ 125). Londres: Institute for Fiscal Studies.

Bustos, J. M. y Villafañe, S. (2011). Asignación Universal por Hijo. Evaluación del impacto en los ingresos de los hogares y el mercado de trabajo. En AAVV, Trabajo, ocupación y empleo $N^{\circ}$ 10 (pp. 175-219). Buenos Aires: SSPTyEL-MTEySS. 
Cacciamali, M. C. (2000). Globalização el processo de informalidade. Economia e Sociedade, 14, 153-174.

Centro de Estudios para el Desarrollo Argentino [CENDA] (2010). La anatomía del nuevo patrón de crecimiento y la encrucijada actual. La economía argentina en el período 2002-2010. Buenos Aires: CENDA-Cara o Ceca.

Centro de Investigación y Formación de la República Argentina [CIFRA] (2012), Información sobre Asignaciones Familiares e impuesto a las ganancias. Cómo afectan a los trabajadores (Documento de Trabajo $\left.N^{\circ} 12\right)$. Buenos Aires: CIFRA. Recuperado de: http:// www.centrocifra.org.ar/docs/CIFRA\%20-\%20DT\%2012 \% 20$\% 20$ Asignaciones $\% 20$ fliares $\% 20 \mathrm{e} \% 20 \mathrm{imp} \% 20$ gananc.pdf

Chávez Molina, E. y Sacco, N. (2015). Reconfiguraciones en la estructura social: dos décadas de cambios en los procesos distributivos. En J. Lindenboim y A. Salvia (coords.), Hora de balance: proceso de acumulación, mercado de trabajo y bienestar. Argentina, 2002-2014 (pp. 289-316). Buenos Aires: EUDEBA.

Coatz, D., García Díaz, F. y Woyecheszen, S. (2010). Acerca de la dinámica creciente de la heterogeneidad productiva y social en la Argentina: un aporte para repensar las políticas públicas a partir del análisis desde la estructura ocupacional. (Boletín Informativo Techint $\mathrm{N}^{\circ}$ 332). Buenos Aires: Techint. Recuperado de: http:// www.uia.org. ar/download.do?id=4492

Cortés, F. (1995). El ingreso de los hogares en contextos de crisis, ajuste y estabilización: un análisis de su distribución en México, 1977-1992. Estudios Sociológicos 13 (37), 91-108.

---- (2000), La distribución de la riqueza en México en épocas de estabilización y reformas económicas. D. F.: M. A. Porrua Grupo Editorial.

Cortés, R. y Marshall, A. (1991). Estrategias económicas, intervención social del Estado y regulación de la fuerza de trabajo. Estudios del trabajo, 1, 21-46.

Curcio, J. y Beccaria, A. (2011). Sistema de Seguridad Social y mercado de trabajo. Evolución de la cobertura en la Argentina entre 1990 y 2010. En C. Danani y S. Hintze (coords.), Protecciones y desprotecciones: la seguridad social en la Argentina (1990-2010) (pp. 61-102). Los Polvorines: UNGS.

Dalle, P., Carrascosa, J., Lazarte, L., Mattera, P. y Ragulich, G. (2015). Reconsideraciones sobre el perfil de la estructura de estratificación y la movilidad social intergeneracional desde las clases populares en Argentina a comienzos del siglo XXI. Lavboratorio. Revista de Estudios sobre Cambio Estructural y Desigualdad Social, 15, 255-280. 
Danani, C. (2009). La gestión de la política social: un intento de aportar a su problematización. En: M. Chiara y M. M. Di Virgilio (orgs.), Gestión de la política social. Conceptos y herramientas (pp. 2552). Buenos Aires: Prometeo-UNGS.

Danani C. y Beccaria, A. (2011). La (contra) reforma previsional argentina 2004-2008: aspectos institucionales y políticoculturales del proceso de transformación de la protección. En Danani, C. y Hintze, S. (coords.), Protecciones y desprotecciones: la seguridad social en la Argentina 1990-2010 (pp. 103-152). Los Polvorines: UNGS.

Datt, G. y Ravallion, M. (1992). Growth and Redistribution Components in Poverty Measures: A Decomposition with applications to Brazil and India in the 1980's. Journal of Developments Economics, 38, 275-295.

Donza, E. (2015). Cambios en las capacidades de consumo en la estructura social urbana. En J. Lindenboim y A. Salvia (coords.), Hora de balance: proceso de acumulación, mercado de trabajo y bienestar. Argentina, 2002-2014 (pp. 317-350). Buenos Aires: EUDEBA.

Donzelot, (2007 [1985]). La invención de lo social. Buenos Aires: Nueva Visión.

Esping-Andersen, G. (1990). The Three Worlds of Welfare Capitalism. Cambridge: Polity Press.

Filgueira, F. (2015). Modelos de desarrollo, matriz del Estado social y herramientas de las políticas sociales latinoamericanas. En S. Cecchini, F. Filgueira, R. Martínez y C. Rossel (eds.): Instrumentos de protección social. Caminos latinoamericanos hacia la universalización (pp. 49-84). Santiago de Chile: CEPAL.

Fine, B (2003). Labour Market Theory. A Constructive Reassessment. Londres: Routledge / Taylor \& Francis.

Fleury, S. (1997). Estado sin ciudadanos. Seguridad social en América Latina. Buenos Aires: Lugar Editorial.

Gaggero, A., Schorr, M. y Wainer, A. (2014) Restricción eterna. El poder económico durante el kirchnerismo. Buenos Aires: Crisis y Futuro Anterior.

Groisman, F. (2011). Argentina: Los hogares y los cambios en el mercado laboral (2004-2009). Revista de la CEPAL, 104, 81-102.

---- (2013). Gran Buenos Aires: Polarización del ingreso, clase media e informalidad laboral (1974-2010). Revista de la CEPAL, 109, 85-105.

Heintz, J. y Razavi, S. (2012). Social Policy and Employment: Rebuilding the Connections (WIEGO Policy Brief Social Protection $\mathrm{N}^{\circ} 12$ ), Ginebra: UNRISD. 
Hopp, M.V. (2016). Potencialidades y límites del programa Argentina Trabaja en dos barrios populares del conurbano bonaerense. DAAPGE, 16 (27), 7-35.

Instituto Nacional de Estadística y Censos [INDEC] (2003). La nueva Encuesta Permanente de Hogares de Argentina. Buenos Aires: INDEC.

Infante, R. (2011). El desarrollo inclusivo en América Latina y el Caribe. Ensayos sobre políticas de convergencia productiva para la igualdad. Santiago de Chile: CEPAL.

Martínez Franzoni, J. (2005). Regímenes de bienestar en América Latina: consideraciones generales e itinerarios regionales. Revista Centroamericana de Ciencias Sociales, 2 (2), 41-77.

Ministerio de Trabajo, Empleo y Seguridad Social (2008). Boletín Estadístico de la Seguridad Social.

---- (2009). Boletín Estadístico de la Seguridad Social.

(2012). Boletín Estadístico de la Seguridad Social.

Monza, A. y López, N. (1995). Un intento de estimación del sector informal urbano en la Argentina. Desarrollo Económico, 35 (139), 467-474.

O'Connor, J. (2009 [1977]). The Fiscal Crisis of the State, New Jersey: Transaction Publishers.

Offe, C. (1984). Contradictions on the Welfare State. Londres: Hutchinson.

Oliveira, O. y Salles, V. (2000). Reflexiones teóricas para el estudio de la reproducción de la fuerza de trabajo. En E. de la Garza Toledo (coord.) Tratado latinoamericano de sociología del trabajo (pp. 619-643). D. F.: El Colegio de México, FLACSO, UNAM, Fondo de Cultura Económica.

Piva, A. (2015). Economía y política en la Argentina kirchnerista, Buenos Aires: Batalla de Ideas.

Poy, S. (2016). Cambios en la participación laboral de los hogares y en los niveles de bienestar económico. Argentina en los años post-reformas (2003-2014)". Estudios del Trabajo, 51$52, \mathrm{~s} / \mathrm{p}$.

(2017). Heterogeneidad de la estructura ocupacional y segmentación del mercado de trabajo. Gran Buenos Aires, 1974-2014. Trabajo y Sociedad, 29, 353-376.

Programa Regional de Empleo para América Latina y el Caribe [PREALC] (1978). Sector Informal. Funcionamiento y Políticas. Santiago de Chile: OIT.

Rofman, R. y Oliveri, L. (2012). Un repaso sobre las políticas de protección social y la distribución del ingreso en la Argentina. Económica, 58, 97-128. 
Salvia, A. (2007). Consideraciones sobre la transición a la modernidad, la exclusión social y la marginalidad económica. Un campo abierto a la investigación social y al debate político. En A. Salvia y E. Chávez Molina (comps.) Sombras de una marginalidad fragmentada. Aproximaciones a la metamorfosis de los sectores populares de la Argentina (pp. 25-65). Buenos Aires: Miño y Dávila.

---- (2012). La Trampa Neoliberal. Un estudio sobre los cambios en la heterogeneidad estructural y la distribución del ingreso en la Argentina: 1992-2003. Buenos Aires: EUDEBA.

----- (2016) Heterogeneidad estructural y marginalidad económica en un contexto de políticas heterodoxas. En A. Salvia y E. Chávez Molina (coords.), Claves sobre la marginalidad económica y la movilidad social. Buenos Aires: Biblos.

Salvia, A.; Poy, S. y Vera, J. (2016). La política social y sus efectos sobre la pobreza durante distintas etapas macroeconómicas. Argentina, 1992-2012. Revista Desarrollo y Sociedad, 76 (2), 165-203.

---- (2015). Cambios y continuidades en la estructura ocupacional urbana argentina. En J. Lindenboim y A. Salvia (coords.), Hora de balance: proceso de acumulación, mercado de trabajo y bienestar. Argentina, 2002-2014 (pp. 133-172), Buenos Aires: EUDEBA.

Tokman, V. (2000). El sector informal posreforma económica. En: Carpio, J., Klein, E. e I. Novacovsky (comps.). Informalidad y exclusión social (pp. 65-80). Buenos Aires: Fondo de Cultura Económica-SIEMPRO-OIT.

Torrado, S. (1992). La estructura social de la Argentina (1945-1983). Buenos Aires: Ediciones de la Flor.

----- (2006 [1982]). El enfoque de las estrategias familiares de vida en América Latina. Orientaciones teórico-metodológicas. En Familia y diferenciación social. Cuestiones de método (pp. 1132). Buenos Aires: EUDEBA.

Trujillo, L. y Villafañe, S. (2012). Dinámica distributiva y políticas públicas: dos décadas de contrastes en la argentina contemporánea. En M. Novick y S. Villafañe (comps.) Distribución del ingreso. Enfoques y políticas públicas desde el Sur (pp. 227-261). Buenos Aires: MTEYSS-PNUD. 